\title{
The Enteral Insulin-Stimulation after Pancreas Transplantation in the Pig
}

\author{
S. Lindkær Jensen, O. Vagn Nielsen and C. Kühl \\ Dept. of Surgical Gastroenterology (C), Rigshospitalet, and Dept. of Internal Medicine (T), Bispebjerg Hospital, University of Copenhagen, \\ Copenhagen, Denmark
}

Summary. The insulin responses to an oral glucose tolerance test (OGTT) and in intravenous glucose infusion (IVGI), designed to copy the changes in serum glucose concentrations found during OGTT, were measured in four pigs before and after heterotopic pancreatico-duodenal allotransplantation and total pancreatectomy. After transplantation and total pancreatectomy a remarkable hyperinsulinaemia occurred during OGTT and IVGI, reflected by an almost two-fold increment in the insulinogenic index after transplantation. This finding might be explained by drainage of the transplanted pancreas into the systemic circulation instead of the portal vein. The magnitude of the enteral stimulus, i. e. the incretin effect on insulin secretion during OGTT was unchanged after transplantation, suggesting that the incretin effect is not mediated by neural influences upon the endocrine pancreas.

Key words: Glucose, incretin, insulin secretion, pancreatic transplantation, pigs.

Oral glucose induces an insulin response more than twice as large as that induced by intravenous glucose [1-4]. The mechanism behind this phenomenon, termed incretin [5], has received much attention, but its nature has not yet been entirely explained. The incretin effect has mainly been conceived as being of hormonal nature [6-11]. However, it might also be due to neural augmentation of the insulin response [4, 12-14], though until now no studies have excluded this possibility.

The present study was designed to evaluate the necessity of pancreatic innervation on the incretin effect in pigs by studying the effect of heterotopic pancreatic allotransplantation on the insulin responses to oral and intravenous glucose administration.

\section{Material and Methods}

Eight healthy pigs of Danish Landrace weighing 29-34 kg were used in the study.

The operative procedure has been described in detail previously [15]. In short, total pancreaticoduodenectomy was performed in the donor pig, with resection of an $8 \mathrm{~cm}$ long segment of aorta containing both the coeliac and the superior mesenteric arteries. In the recipient pigs pancreaticoduodenal transplantation was as follows: The infrarenal vena cava and the abdominal aorta were exposed for approximately $8 \mathrm{~cm}$. The distal end of the donor aortic segment was anastomosed end-to-side to the abdominal aorta of the recipient and the donor portal vein joined end-to-side to the inferior vena cava of the recipient. The duodenal segment was anastomosed end-to-side to the upper part of jejunum. Total pancreatectomy was performed in the recipient pig one week after transplantation. Penicillin was given during the first postoperative week. Immunosuppressive therapy was not given.

The mean survival time of the four pigs was 73.5 days (range 35-98 days). They remained normoglycaemic for an average of 63.3 days (range 21-91 days). During the investigative period all pigs were in good clinical condition without any signs of malabsorptive disorders. After death the pigs were autopsied and, to insure that there were no remaining parts of pancreatic tissue after the total pancreatectomy, the pancreatic bed was investigated by a trained pathologist (M. Petri), macroscopically as well as microscopically. In no case was residual pancreatic tissue found. 
All tests were performed in conscious animals. Nine and four days before transplantation an oral glucose tolerance test (OGTT) and an intravenous glucose infusion (IVGI) were performed. The OGTT and the IVGI were repeated in the same order 9 and 13 days after transplantation and total pancreatectomy. All tests began, after an overnight fast, between 8:00 and 9:00 a. m. Blood samples were collected from an i. v. cannula inserted into the left external jugular vein. After separation serum was stored at $-25^{\circ} \mathrm{C}$ until analyzed.

\section{Experimental Procedure}

\section{Oral Glucose Tolerance Test}

The pigs were given $50 \mathrm{~g}$ of glucose as a $50 \%$ solution through a gastric tube. Blood samples were drawn 10 and 5 min before glucose loading and 10,20,30,50, $60,90,120,150$, and 180 min after.

\section{Intravenous Glucose Infusion}

Glucose was administered according to Rehfeld [16]. In accordance with the observation that two thirds of the glucose given orally are normally extracted by the liver [3], all pigs were given $16.7 \mathrm{~g}$ glucose intravenously before transplantation in order to copy the blood glucose concentration curve of the OGTT. When insulin was diverted from the portal vein the glucose extraction by the liver secmed to be reduced, since it was necessary to infuse larger amounts of glucose in order to copy the oral glucose curves after transplantation. Thus after transplantation the four pigs received 18.5, 21.0, 24.5, and $34.5 \mathrm{~g}$ of glucose, respectively. Glucose was given in concentrations from 33 to $50 \%$ by an infusion pump into the right internal jugular vein. Blood samples were drawn from the left external jugular vein following the protocol of the OGTT. Serum glucose concentrations during IVGI were frequently controlled by means of the Dextrostix-Eyetone System (Miles Laboratories, Inc. Elkhart, Indiana [17]) and adjusted to the serum glucose concentrations found during OGTT.

\section{Laboratory Analysis}

Serum glucose concentrations were estimated by a hexokinase method [18]. Serum insulin concentration was measured radioimmunochemically; detection limit, precision, accuracy, and specificity of the assay have been given in detail elsewhere [19].

\section{Calculations}

The integrated insulin response was calculated as the area below the serum insulin concentration curve from 0 to $180 \mathrm{~min}$ using the fasting level as base line. The insulinogenic index [20] for the whole test was calculated by dividing the incremental insulin area above fasting baseline by the incremental glucose area above fasting baseline. The magnitude of the enteral stimulus, i. e. the incretin effect on insulin secretion during OGTT, was calculated from the following formula: Incremental insulin area ${ }_{\text {OGTT }}$ - incremental insulin area $_{\mathrm{IVGI}} /$ incremental insulin area ${ }_{\mathrm{IVGI}}$. The significance of differences between means was estimated by Student's $t$-test for paired observations. $P$-values less than 0.05 were considered significant.

\section{Results}

The variations in glucose concentrations in serum are shown in Figure 1 and 2. The intravenous glucose curve duplicated the oral glucose curve perfectly, before as well as after transplantation. The peak glucose concentrations after transplantation were reached 10 min earlier in all tests than before transplantation. Before transplantation, the mean fasting serum glucose concentrations before OGTT and IVGI were $2.80 \pm 0.08 \mathrm{mmol} / \mathrm{l}$ and $2.75 \pm 0.13 \mathrm{mmol} / 1$, respectively. 'The maximum glucose concentration reached during OGTT was $13.3 \pm 0.5 \mathrm{mmol} / 1$ and during IVGI $13.0 \pm 0.13 \mathrm{mmol} / 1$. After transplantation, the mean basal serum glucose concentrations before the two tests were $5.0 \pm 0.5 \mathrm{mmol} / 1$ and $5.0 \pm 0.1 \mathrm{mmol} / 1$, both concentrations being significantly higher than the corresponding concentration before transplantation ( $\mathrm{p}<0.001$ ). After transplantation, the mean maximum serum glucose concentration during OGTT was $16.3 \pm 0.4 \mathrm{mmol} / \mathrm{l}$ and during IVGI $15.8 \pm 0.2$ $\mathrm{mmol} / \mathrm{l}$, both levels being significantly higher than the corresponding preoperative values $(\mathrm{p}<0.01)$.

The variations in insulin concentrations in serum during OGTT and IVGI pre- and postoperatively are shown in Figures 1 and 2. Before transplantation, serum insulin concentration rose during OGTT from $29.3 \pm 4.1 \mathrm{pmol} / \mathrm{l}$ in the basal state to a peak value of $266.3 \pm 18.6 \mathrm{pmol} / 1$ after $60 \mathrm{~min}(\mathrm{p}<0.01)$. During IVGI the corresponding values were $27.6 \pm 2.8$ $\mathrm{pmol} / \mathrm{l}$ and $69.0 \pm 7.6 \mathrm{pmol} / \mathrm{l}(\mathrm{P}<0.01)$. During OGTT serum insulin concentrations were uniformly higher than during IVGI, preoperatively as well as postoperatively. After transplantation, the basal serum insulin concentration rose from $54.8 \pm 0.1$ $\mathrm{pmol} / \mathrm{l}$ to a peak value of $309.1 \pm 49.7 \mathrm{pmol} / 1$ after 60 

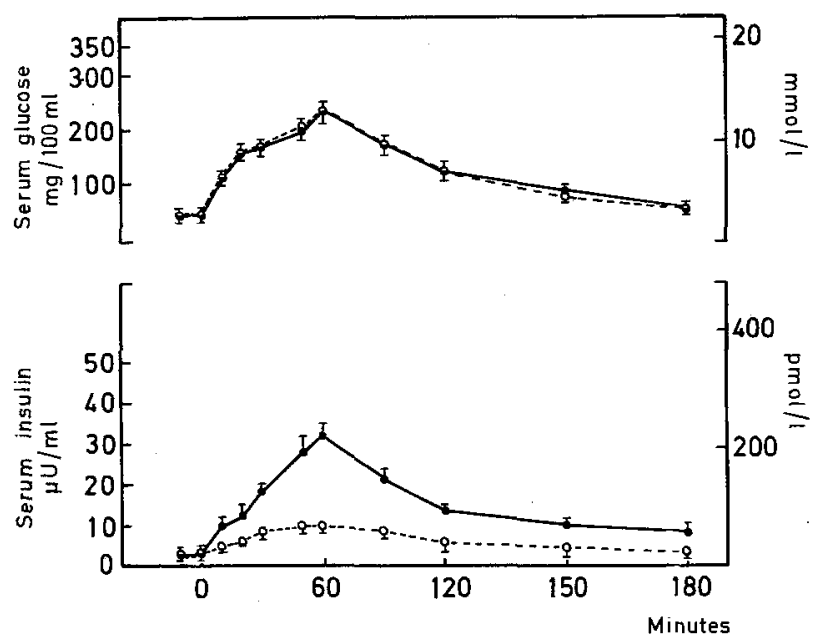

Fig. 1. Serum glucose and insulin concentration during a $50 \mathrm{~g}$ oral glucose tolerance test $(\bullet-)$ ) and intravenous glucose infusion test $(\mathrm{O}-\mathrm{O})$ designed to copy the oral glucose curve in four healthy pigs. The concentrations are indicated as mean \pm SEM

min; during the IVGI the corresponding values were $46.9 \pm 3.5 \mathrm{pmol} / 1$ and $131.1 \pm 11.7 \mathrm{pmol} / \mathrm{l}$. The basal serum insulin concentration was enhanced after transplantation $(\mathrm{p}<0.01)$.

The basal Insulin: Glucose ratio was unaffected by transplantation, being $1.5 \pm 0.1$ before and $1.5 \pm 0.2$ after. Before transplantation, the mean insulinogenic index during OGTT and IVGI was $2.6 \pm 0.2$ and 0.53 \pm 0.1 , respectively. After transplantation significantly higher mean insulinogenic indices were found during OGTT $(4.4 \pm 0.7 ; p<0.05)$ and IVGI $(0.74 \pm 0.1 ; p$ $<0.05$ ).

The mean enteral index was not significantly changed after transplantation: $3.6 \pm 0.6$ compared to the preoperative value $4.7 \pm 1.5$

\section{Discussion}

The main conclusion that can be drawn from the present study is that the incretin effect does not necessarily require neural stimulation, in as much as the enteral index remained unaffected by heterotopic pancreatic transplantation.

Until now the incretin effect has been considered as being of hormonal nature, being mediated by one or more of the gastrointestinal hormones $[10,11]$. Conclusive data have, however, not been presented in favour of one of the known gastrointestinal hormones. The present study and the observation that the enteral insulin stimulation is well preserved in man after truncal vagotomy [21] suggest that the incretin effect
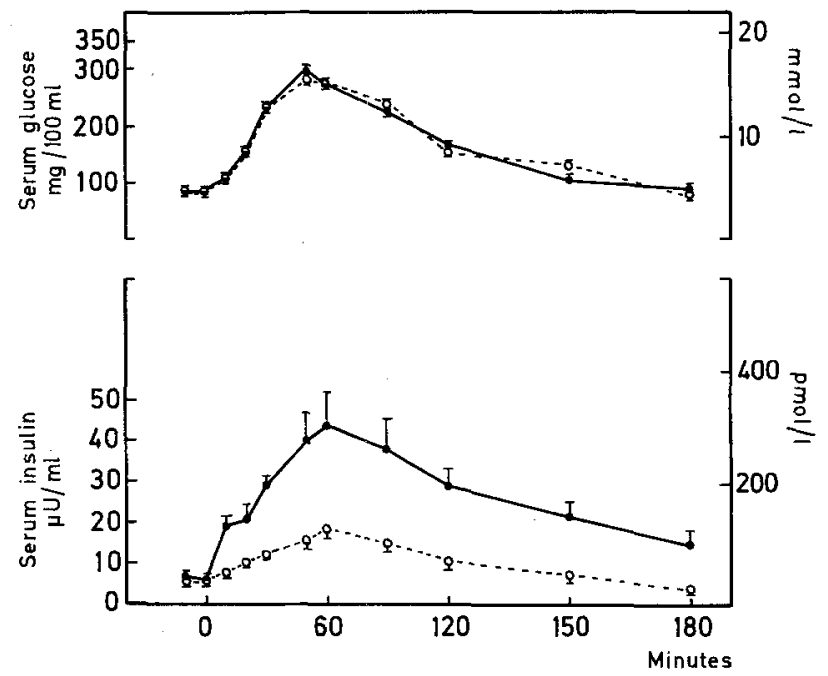

Fig. 2. Serum glucose and insulin concentration during a $50 \mathrm{~g}$ oral glucose tolerance test $(\bullet-\bullet)$ and intravenous glucose infusion test $(\mathrm{O}-\mathrm{O}$ ) designed to copy the oral glucose curve in the four pigs shown in Fig. 1, but investigated after total pancreatectomy and pancreatic transplantation. The concentrations are indicated as mean \pm SEM

probably is of humoral nature. The results concerning the enteral insulin stimulation in man are however, contradictory, in as much as Humphrey et al. [22] recently found, that truncal vagotomy led to a diminished insulin response to oral glucose, whereas the insulin response to intravenously administered glucose was unchanged.

This study has tested the hypothesis that the incretin effect could be mediated via neural impulses reaching the endocrine pancreas. Most vertebrate species have a rich supply of autonomic neurones to the islets of Langerhans. Both adrenergic and cholinergic fibres innervate the secretory cells [23]. Stimulation of the parasympathetic nervous system leads to insulin secretion [23], but apparently no studies have differentiated between the direct effect of parasympathetic stimulation of the islets from possible parasympathetic stimulation of the gastrointestinal hormones.

In the basal state as well as during OGTT and IVGI,- the concentration of insulin in serum was significantly enhanced after transplantation. In the basal state this enhancement seemed to counterbalance an identical enhancement of serum glucose, reflected by the constancy of the insulin: glucose ratio. In contrast, a remarkable hyperinsulinaemia was present during OGTT and IVGI, reflected by an almost two-fold increment in the insulinogenic index after transplantation. These findings suggest that the glucose-insulin feed-back mechanism [24] was preserved in the transplanted pancreas in the basal state only. The greater insulin concentrations observed postoperatively may be explained by the drainage of the transplanted pan- 
creas into the systemic circulation instead of the portal vein. Since the liver extracts about half of the amount of insulin that is presented to it [25], this figure might explain the almost two-fold increment of the insulinogenic index after transplantation.

Following transplantation, the tolerance to oral glucose ingestion decreased in spite of elevated levels of insulin in serum. This finding might also be explained by the fact that insulin was secreted into the systemic circulation, since normally two-thirds of glucose given orally are extracted by the liver [3]. In cases with diversion of insulin secretion away from the portal vein this fraction might be smaller and hyperglycaemia consequently occur. Because the tolerance to intravenously administered glucose is largely independent of the liver [26] this explanation is supported by our finding of an unaffected tolerance in the same pigs with heterotopic pancreatic allotransplantation [15].

The unchanged incretin effect after transplantation and thus denervation of the pancreas suggests that the incretin effect probably is of humoral nature. Very recent studies $[27,28]$ indicate that of the known gastrointestinal hormones, gastric inhibitory polypeptide (GIP) is the most likely candidate for the incretin activity, at least during carbohydrate ingestion.

Acknowledgements. The skillful technical assistance of Linda Aarelaid, Connie Breiner, Letty Klarskov, and Sörn Hågen Nielsen is gratefully acknowledged.

\section{References}

1. McIntyre, N., Holdsworth, C. D., Turner, D. S.: New interpretation of oral glucose tolerance. Lancet $1964 \mathrm{I}, 20-21$

2. Elrick, H., Stimmler, L., Hlad, C. J., Arai, Y.: Plasma insulin response to oral and intravenous glucose administration. J. clin. Endocr. 24, 1076-1082 (1964)

3. Perley, M. J., Kipnis, D. M.: Plasma insulin responses to oral and intravenous glucose: studies in normal and diabetic subjects. J. clin. Invest. 46, 1954-1962 (1967)

4. Rehfeld, J. F., Stadil, F., Baden, H., Fischerman, K.: The enteral insulin-stimulation after Whipple's operation. Diabetologia 11, 207-210 (1975)

5. Zunz, E., LaBarre, J.: Hyperinsulinémie consécutive a l'injection de solution de secrétine non hypotensive. C. R. Soc. Biol. (Paris) 98, 1435-1438 (1928)

6. Dupré, J., Beck, J. C.: Stimulation of release of insulin by an extract of intestinal mucosa. Diabetes 15, 555-559 (1966)

7. McIntyre, N., Holdsworth, C. D., Turner; D. S.: Intestinal factors in control of insulin secretion. J. clin. Endocr. 25, 1317-1324 (1965)

8. Ohneda, A., Parada, E., Eisentraut, A. M., Unger, R. H.: Characterization of response of circulating glucagon to intraduodenal and intravenous administration of amino acids. $J$. clin. Invest. 47, 2305-2322 (1968)

9. Rehfeld, J. F., Juhl, E., Quaade, F.: The intestinal insulinotropic action after jejunoileostomy. Metabolism 19, 529-538 (1970)

10. Rehfeld, J. F.: Gastrointestinal hormones and insulin secretion. Scand. J. Gastroent. 7, 289-292 (1972)
11. Creutzfeldt, W.: Insulin-releasing factors of the gastrointestinal mucosa (Incretin). Gastroenterology 67, 748-750 (1974)

12. Unger, R. H., Eisentraut, A. M.: Entero-insular axis. Arch. intern. Med. 123, 261-266 (1969)

13. Dupré, J.: Regulation of the secretions of the pancreas. Ann. Rev. Med. 21, 261-316 (1970)

14. Fischer, U., Hommel, H., Ziegler, M., Jutzi, E.: The mechanism of insulin secretion after oral administration. III. Investigations on the mechanism of a oral administration. Diabetologia 8 , 385-390 (1972)

15. Jensen, S. L., Nielsen, O. V., Kühl, C., Petri, M.: Experimental heterotopic pancreaticoduodenal allotransplantation. Studies in the unimmunosuppressed pig. (Submitted for publication)

16. Rehfeld, J. F., Stadil, F.: The glucose-induced gastro-intestinal stimulation of insulin secretion in man: relation to age and gastrin release. Europ. J. clin. Invest. 5, 273-283 (1975)

17. Schersten, H. S., Kühl, C., Hollender, A., Ekman, R.: Blood glucose measurement with dextrostix and new reflectance meter. Brit. med. J. 1974 III, 384-387

18. Richterich, R., Dauwalder, H.: Zur Bestimmung der PlasmaGlucosekonzentration mit der Hexokinase/Glucose-6-Phosphatdehydrogenase-Methode. Schweiz. med. Wschr. 101, 615-618 (1971)

19. Kühl, C.: Glucose metabolism during and after pregnancy in normal and gestational diabetic women. I. Influence of normal pregnancy on serum glucose and insulin secretion during basal fasting conditions and after a challenge with glucose. Acta endocr. 79, 709-719 (1975)

20. Seltzer, H. S., Allen, E. W., Herron, A. L., Brennan, M. T.: Insulin secretion in response to glycemic stimulus. Relation to delayed initial release to carbohydrate intolerance in mild diabetic mellitus. J. clin. Invest. 46, 323-334 (1967)

21. Lund, B., Aagård, P., Deckert, T.: Effect of vagotomy on insulin release after oral and intravenous glucose administration. Scand. J. Gastroent. 10, 777-780 (1975)

22. Humphrey, C. S., Dykes, J. R. W., Johnston, D.: Effects of truncal, selective, and highly selective vagotomy on glucose tolerance and insulin secretion in patients with duodenal ulcer. Brit. med. J. 1975 II, 112-116

23. Woods, S. C., Porte, D.: Neural control of the endocrine pancreas. Physiol. Rev. 54, 596-619 (1974)

24. Turner, R. C., Oakley, N. W., Nabarro, J. D. N.: Control of basal insulin secretion with special reference to the diagnosis of insulinomas. Brit. med. J. 1974 II, 132-135

25. Camu, F.: Hepatic balances of glucose and insulin in response during glucose infusion in dogs. Europ. J. clin. Invest. 5, 101-108 (1975)

26. Lorentz, D., Creutzfeldt, W.: Leberzellverfettung, Glucosetoleranz und Tolbutamidtest nach Ableitung des Pankreasvenenblutes und des Pfortaderblutes von der Leber. Z. ges. exp. Med. 140, 35-50 (1966)

27. Pederson, R. A., Schubert, H. E., Brown, J. C.: Gastric inhibitory polypeptide. Its physiologic release and insulinotropic action in the dog. Diabetes 24, 1050-1056 (1975)

28. Schauder, P., Brown, J. C., Frerichs, H., Creutzfeldt, W.: Gastric inhibitory polypeptide: effect on glucose-induced release from isolated rat pancreatic islets in vitro. Diabetologia 11, 483-484 (1975)

Received: May 5, 1976, and in revised form: August 16, 1976

Dr. S. Lindkær Jensen

Dept. of Surgical Gastroenterology C

Rigshospitalet

Blegdamsvej 9

DK-2100 Copenhagen $\varnothing$

Denmark 